\title{
Influence de l'azote des constituants pariétaux sur la dégradabilité in sacco de l'azote des aliments
}

\author{
P Chapoutot, F Ternois, D Sauvant \\ Station de Nutrition et Alimentation (INRA) de I'INA-PG, \\ 16, rue C-Bernard, 75231 Paris Cedex 05, France
}

Summary - In sacco nitrogen ( $N$ ) degradability values (DT) of 36 feeds were correlated with the $N$ solubility or the $N$ tractions present in the neutral and acid detergent fiber residues (NDF, ADF). Moreover, combinations of these parameters improved the prediction of the undegradable $N$ fraction (RSD $=6.9$ ).

Introduction - Le système des protéines digestibles dans l'intestin (PDI) s'appuie en particulier sur la connaissance de la dégradabilité théorique de l'azote (DT) mesurée par la technique des sachets de nylon (Vérité et Peyraud, 1988). Le travail présenté a pour objet d'évaluer l'intérêt des fractions azotées des composants NDF et ADF pour expliquer les variations de la proportion d'azote dégradable d'un ensemble diversifié d'aliments.

Matériel et Méthodes - L'étude a porté sur 53 échantillons de 36 matières premières (tableau I). Les analyses d'azote, de NDF et d'ADF ont été appliquées sur ces échantillons; en outre, ont été mesurées la solubilité de l'azote (S en \%), l'azote des fractions NDF et ADF (NNDF et $N$-ADF en \% $N$ total). La DT (en \%) a été calculée à partir des résultats des mesures de dégradation in sacco selon la méthode décrite par Chapoutot et al (1988). Lorsque plusieurs échantillons ont été étudiés pour une même matière première, seules les valeurs moyennes ont été retenues dans l'étude.

Résultats et Discussion - La DT des aliments est négativement et significative- ment liée à leurs teneurs en NDF $(R=$ $-0,68$; écart type résiduel $(E T R)=13,9$ ) et $\operatorname{ADF}(R=0,69 ; E T R=13,6)$, ainsi qu'aux proportions d'azote insoluble $(R=-0,81$; $E T R=11,0$ ) ou retenues dans les fractions $\operatorname{ADF}(R=-0,76 ; E T R=12,3)$ ou $\operatorname{NDF}(R=-0,81 ; E T R=11,0)$.

Cependant, une plus grande part de variation de cette fraction peut être expliquée par la combinaison des contenus azotés des fractions NDF et ADF : $D T=$ $80,3-0,37 \mathrm{~N}-\mathrm{NDF}-0,35 \mathrm{~N}-\mathrm{ADF}(n=$ 36; $R=0,843 ; E T R=10,3$ ).

En outre, la prise en compte simultanée de la teneur en ADF des aliments et de la fraction azotée qui y est associée améliore nettement la précision de la prédiction à partir de la solubilité de l'azote : $D T=56,9+0,50 \mathrm{~S}-0,21$ ADF $-0,36 \mathrm{~N}-$ ADF $(n=36 ; R=0,936 ; E T A=6,9)$.

En conclusion, la prise en compte de la fraction azotée incluse dans les constituants NDF et ADF permet, comme l'a suggéré van Soest et al (1980), d'obtenir une meilleure précision qu'avec la solubilité seule pour prévoir la dégradation des matières azotées des aliments dans le rumen. 
Tableau I. Caractéristiques des aliments.

\begin{tabular}{|c|c|c|c|c|c|c|c|c|}
\hline Aliments & $\begin{array}{r}n b \\
e c h\end{array}$ & $\begin{array}{c}M A T \\
(\% \mathrm{~ms})\end{array}$ & $\begin{array}{c}N D F \\
(\% m s)\end{array}$ & $\begin{array}{c}A D F \\
(\% \mathrm{~ms})\end{array}$ & $\underset{(\%)}{S}$ & $\begin{array}{l}D T \\
(\%)\end{array}$ & $\begin{array}{c}N-N D F \\
(\% N \text { tot })\end{array}$ & $\begin{array}{c}N-A D F \\
(\% N \text { tot })\end{array}$ \\
\hline Avoine & 1 & 9,0 & 30,9 & 15,5 & 26 & 77 & 4,2 & 2,7 \\
\hline Blé & 1 & 12,9 & 9,6 & 3,1 & 26 & 79 & 6,8 & 0,9 \\
\hline Maïs & 1 & 10,1 & 11,2 & 2,8 & 15 & 46 & 10,3 & 1,1 \\
\hline Son fin & 1 & 17,1 & 35,3 & 12,4 & 36 & 79 & 8,2 & 2.7 \\
\hline Corn gluten feed & 1 & 20,3 & 39,0 & 9,3 & 48 & 71 & 11,5 & 2,4 \\
\hline Drêches maïs & 1 & 9,9 & 67,2 & 14,5 & 16 & 58 & 36,2 & 3,6 \\
\hline Drêches blé & 3 & 35,5 & 34,6 & 12,3 & 17 & 66 & 10,6 & 2,4 \\
\hline Pois & 1 & 23,2 & 16,5 & 6,8 & 66 & 89 & 4,0 & 0,4 \\
\hline Féverole & 1 & 27,8 & 14,7 & 6,7 & 67 & 90 & 1,5 & 0,5 \\
\hline Tourteau (T) arachide & 1 & 46,4 & 20,5 & 14,5 & 55 & 83 & 3,8 & 1,9 \\
\hline T coprah & $i$ & 23,4 & 65,3 & 32,1 & 10 & 58 & 74,7 & 7,3 \\
\hline T germes maïs & 1 & 25,4 & 66,5 & 30,9 & 10 & 64 & 31,3 & 4,6 \\
\hline Coques soja & 2 & 13,5 & 64,7 & 44,2 & 22 & 55 & 36,7 & 7.4 \\
\hline Coques colza & 1 & 17,8 & 50,0 & 34,1 & 20 & 39 & 53,0 & 27,9 \\
\hline Coques tournesol & 1 & 4,7 & 84,7 & 64,6 & 19 & 40 & 53,6 & 41,8 \\
\hline Coques arachide & & & & & & & & \\
\hline$+5 \% \mathrm{NaOH}$ & 1 & 6,5 & 77,8 & 61,4 & 13 & 40 & 99,9 & 39,2 \\
\hline Grignons olives & 1 & 8,8 & 71,2 & 50,0 & 4 & 27 & 94,3 & 70,9 \\
\hline Marc pommes & 1 & 5,5 & 43,4 & 31,7 & 23 & 43 & 63,9 & 54,9 \\
\hline Marc raisin & 1 & 12,3 & 73,9 & 61,5 & 16 & 32 & 64,8 & 15,9 \\
\hline Pépins raisin & 4 & 9,6 & 73,3 & 60,3 & 26 & 53 & 42,2 & 34,2 \\
\hline Pulpe raisin & 3 & 14,6 & 69,0 & 57,4 & 11 & 20 & 76,5 & 61,3 \\
\hline Pulpe agrumes & 1 & 8,6 & 21,3 & 13,8 & 40 & 71 & 27,5 & 6,1 \\
\hline Ecorces oranges & 1 & 6,2 & 34,4 & 25,8 & 28 & 58 & 39,1 & 12,7 \\
\hline Pulpe tomates & 2 & 19,3 & 56,1 & 43,6 & 32 & 60 & 36,6 & 15,2 \\
\hline Pulpe betteraves & 7 & 9,2 & 54,0 & 23,9 & 13 & 55 & 70,7 & 9,0 \\
\hline Racines endives & 1 & 4,3 & 18,1 & 14,0 & 42 & 74 & 45,9 & 24,0 \\
\hline Salsifis & 1 & 11,8 & 21,6 & 17,6 & 80 & 86 & 9,4 & 7,1 \\
\hline Sp pommes de terre a & 1 & 10,1 & 7,2 & 5,2 & 44 & 70 & 5,4 & 3,9 \\
\hline Sp épinards & 1 & 35,8 & 38,2 & 6,6 & 16 & 57 & 56,0 & 1,9 \\
\hline Sp haricots verts b & 1 & 19,3 & 31,8 & 25,8 & 31 & 64 & 14,4 & 5,7 \\
\hline Sp petits pois ${ }^{b}$ & 3 & 23,2 & 27,0 & 16,7 & 63 & 82 & 5,0 & 1,7 \\
\hline Fanes pois & 1 & 14,2 & 41,2 & 27,9 & 50 & 73 & 23,2 & 3,5 \\
\hline Foin luzerne & 1 & 17,2 & 47,2 & 26,4 & 31 & 69 & 43,3 & 5,1 \\
\hline Luz desh + T soja $(50 / 50)$ & 1 & 47,6 & 22,1 & 15,3 & 39 & 74 & 10,6 & 1,4 \\
\hline Luz desh $1+$ urée $(90 / 10)$ & 1 & 46,0 & 43,6 & 26,4 & 70 & 89 & 20,6 & 3,9 \\
\hline Luz desh $2+$ uree $(90 / 10)$ & 1 & 48,9 & 45,1 & 28,3 & 77 & 87 & 11,2 & 3,2 \\
\hline
\end{tabular}

a Sous-produits de fabrication de purée. ${ }^{b}$ Sous-produits de conserverie.

Chapoutot P, Sauvant D, Lefrançois $S$ (1988) Reprod Nutr Dev 28, 167-168 van Soest PJ, Sniffen CJ, Mertens DR, Fox DG, Robinson PH, Krishnamoorthy U (1980) In:
Protein Requirements for Cattle. (Owens FN, ed), Oklahoma State University, 265-279

Vérité R, Peyraud JL (1988) In: L'alimentation des Bovins, Ovins et Caprins (Jarrige R, ed), INRA, Paris, 73-93 